\title{
ОПТИМИЗАЦИЯ СБОРА АНАМНЕЗА НА ОРТОДОНТИЧЕСКОМ ПРИЕМЕ
}

\author{
Цветкова Мария Александровна \\ К.м.н., ФГБУ ВО «МосковскИй государственный \\ медико-стоматологический университет имени \\ А.И. Евдокимова» \\ tsvetkova-orthodont@inbox.ru \\ Сохов Сергей Талустанович \\ Заслуженный врач РФ, д.м.н., профессор, \\ ФГБУ ВО «Московский государственный медико- \\ стоматологический университет имени \\ А.И. Евдокимова» \\ drsokhov@yandex.ru
}

\section{OPTIMIZATION OF ANAMNESIS COLLECTION BEFORE ORTHODONTIC TREATMENT}

\section{Tsvetkova \\ S. Sohov}

Summary. Aim:

1. To develop a preliminary anamnesis collection questionnaire for orthodontic patients for the quick identification of diseases and / or medications that can affect bone remodeling and the process of orthodontic treatment;

2. Compare the results of its application with the traditional form of the survey.

Materials and methods: anamnesis of 284 patients was collected by the orthodontist using medical record form No. 043-1/y. Then, the same patients were asked to fill out a specially designed questionnaire on their own.

Results: application of specially designed questionnaire made it possible to identify menopausal women $(4.6 \%)$, patients with osteoporosis $(0.7 \%)$, with endoprostheses $(0.7 \%)$, the presence of non-drug allergic reactions in patients $(18.7 \%)$. When collecting anamnesis according to the questionnaire in the medical record form №. 043-1 / $y, 3.9 \%$ of patients did not notify the doctor about taking corticosteroids in the form of sprays or inhalations. When filling out the questionnaire on their own, patients more often indicated taking vitamin D3 (by 15.9\%), Omega 3 (by 11.3\%) and zinc (by 1.8\%).

Conclusions. Reliable and complete information about the patient's health status obtained using a specially designed questionnaire will allow the orthodontist to individualize treatment plan and retention period, taking into account the general somatic and medicinal history.

Keywords: anamnesis, questionnaire, orthodontic treatment.
Аннотация. Профессиональная деятельность врача любой специальности не возможна без тщательного сбора анамнеза.

Цель:

1. Разработать анкету для предварительного сбора анамнеза перед первичным приемом врача-ортодонта для выявления тех заболеваний и/или приема лекарственных препаратов, которые способны влиять на ремоделирование костной ткани и отразиться на процессе ортодонтического лечения;

2. Сравнить результаты её применения с традиционной формой опроса.

Материал и методы исследования: у 284 пациентов, обратившихся на консультацию и лечение, врач-ортодонт собирал анамнез по пунктам, указанным в медицинской карте формы № 043-1/у. Затем, этим же пациентам было предложено самостоятельно заполнить специально разработанную анкету (свидетельство о депонировании № 2051872).

Результаты: при сравнении данных анамнеза, полученных врачом при опросе по форме № 043-1/у и при использовании разработанной нами анкеты, были выявлены существенные различия в полноте получаемой информации. Так, применение анкеты позволило выявить женщин в периоде менопаузы (4,6\%), пациентов с остеопорозом (0,7\%), с эндопротезами $(0,7 \%)$, наличие у пациентов немедикаментозных аллергических реакций (18,7\%). При сборе анамнеза по анкете в медицинской карте формы № 043-1/y, 3,9\% пациентов не уведомили доктора о приеме кортикостероидов в виде спреев или ингаляций. При самостоятельном заполнении опросника пациенты чаще указывали прием витамина D3 (на 15,9\%), 0мега 3 (на 11,3\%) и цинка (на 1,8\%).

Выводы. Достоверные и полные сведения о состоянии здоровья пациента, полученные с помощью специально разработанной анкеты, позволят врачу-ортодонту индивидуализировать план лечения и ретенционный период с учетом общесоматического и лекарственного анамнеза.

Ключевые слова: анамнез, анкета, ортодонтическое лечение. 


\section{Актуальность исслеАования}

5 ффективная и безопасная деятельность врача любой специальности не возможна без опроса пациента о его общесоматическом состоянии здоровья. В своей ежедневной практике врач-ортодонт сталкивается с большим числом пациентов различных возрастных групп с общесоматической патологией и принимающих лекарственные препараты на постоянной основе. Ремоделирование костной ткани, которое происходит в процессе ортодонтического лечения это динамический процесс, требующий координированной клеточной активности между остеобластами, остеоцитами и остеокластами с целью поддержания гомеостаза костной ткани. Большой перечень заболеваний, медикаментов и пищевых добавок могут повлиять на ортодонтическое движение зубов $[1,2]$ за счет прямого влияния на общую физиологию кости, дифференцировку остеокластов, скорость метаболизма кости, ее плотность и степень минерализации [3]. Кроме того, побочные действия лекарств и проявления общесоматической патологии в полости рта, такие, как гиперплазия десны, ксеростомия, эрозивно-язвенные процессы на слизистой рта, повышенный риск развития кариеса и др., способны значительно осложнить течение ортодонтического лечения [4].

Становится очевидным, что врач-ортодонт не может планировать и проводить лечение без учета общесоматического и лекарственного анамнеза.

Согласно приказу министерства здравоохранения № 834н (от 15 декабря 2014 г.) «Об утверждении унифицированных форм медицинской документации, используемых в медицинских организациях, оказывающих медицинскую помощь в амбулаторных условиях, и порядок по их заполнению», на каждого пациента врач-ортодонт должен заполнять медицинскую историю болезни по форме № 043-1/у. Данная форма истории болезни была разработана на кафедре ортодонтии и детского протезирования МГМСУ им. А.И. Евдокимова. Целью ее создания была оптимизация работы врача-ортодонта, а так же систематизированный сбор и хранение максимального объема результатов диагностических исследований. В основной части истории болезни, наряду с другими, есть раздел «Анамнез», а в приложении «Общий медицинский анамнез», содержащие вопросы, которые врач должен задать пациенту.

Однако, по данным Лапиной А.К., [5,6] при анализе степени заполняемости карт по форме № 043-1/у в Москве, информация о перенесенных и сопутствующих заболеваниях содержалась лишь в 46,5\% случаев. Врачи-ортодонты с большим стажем работы значительно реже указывают данные о перенесенных и сопутствую- щих заболеваниях, врачи со стажем работы 20 лет и более в 45,1\% карт не заполняли эту графу в медицинских картах. 46,3\% опрошенных врачей главным недостатком новой формы медицинской карты назвали ее большой объем и значительные временные затраты на заполнение всех необходимых разделов.

Врач вынужден пренебрегать тщательным сбором анамнеза из-за нехватки времени и подходит к опросу пациента формально.

По мнению Шерматовой Ю.В. и коллег [7], предварительное анкетирование позволяет врачу получить более полную информацию о состоянии здоровья пациента и способствует достоверному снижению частоту осложнений в процессе стоматологического лечения. Кроме того, письменное заполнение документа повышает ответственность пациента перед врачом за предоставляемые им сведения о своем здоровье.

\section{Le^ь}

1. Разработать анкету для предварительного сбора анамнеза перед первичным приемом врача-ортодонта для выявления тех заболеваний и/или приема лекарственных препаратов, которые способны влиять на ремоделирование костной ткани и отразиться на процессе ортодонтического лечения;

2. Сравнить результаты её применения с традиционной формой опроса.

\section{Материал и метолы исслеАования}

В исследовании приняли участие 284 пациента, обратившихся на консультацию и ортодонтическое лечение. У всех пациентов врач-ортодонт собирал анамнез по пунктам, указанным в медицинской карте формы № 043-1/у. Затем, этим же пациентам было предложено самостоятельно заполнить анкету, разработанную нами на основе научных материалов отечественной и зарубежной литературы. Было обработано более 300 статей (по базам E-library, Med-line, Cochrane Library, EMBASE, Web of Science и Biosis), посвященных особенностям планирования и проведения ортодонтического лечения у пациентов с различной общесоматической патологией и отягощенным лекарственным анамнезом. Так же анализировалось влияние различных вредных привычек (курение, употребление алкоголя) и особенностей питания на возможный исход ортодонтического перемещения зубов.

Основными требованиями к разработанному опроснику были простота и однозначность вопросов, 
Таблица 1. Первичное анкетирование ортодонтического пациента. Рост/вес Возраст

Есть ли у Вас (Вашего ребенка) следующие заболевания:

- сердечно-сосудистые (инфаркт миокарда, инсульт, пороки сердца, стенокардия, инфекционный

эндокардит)

Были ли когда-нибудь операции на сердце (искусственный сердечный клапан, стент, др)?

Наблюдалось ли повышенное артериальное давление (АД)?

если да, то какие лекарственные препараты Вы (Ваш ребенок) принимаете

- сахарный диабет (1 или 2 типа)

какие лекарства Вы (Ваш ребенок) принимаете по назначению эндокринолога?

какие показатели глюкозы и гликированного гемоглобина

регистрировали в последних анализах крови?

- астма/ обструктивный бронхит

Что может провоцировать приступы?

Частота и степень тяжести приступов?

Какие препараты Вы (Ваш ребенок) принимаете для снятия приступа астмы или бронхита?

- заболевания ЖКТ (язвенная болезнь желудка/ 12-перстной кишки, воспалительные заболевания кишечника, б-нь Крона, язвенный колит, целиакия и др.)

страдаете ли Вы (Ваш ребенок) рефлюксной болезнью

\begin{tabular}{|l|l|}
\hline Да & Нет \\
\hline Да & Нет \\
\hline Да & Нет
\end{tabular}

Нет

\begin{tabular}{|l|l|} 
Да & Нет \\
\hline
\end{tabular}

если да, принимаете ли Вы (Ваш ребенок) антацидные препараты или ингибиторы протонной помпы (омепрозол, пантопрозол и др.)

\begin{tabular}{l|l|l}
\hline - заболевания печени & Да & Нет \\
\hline - заболевания почек & Да & Нет \\
$\begin{array}{l}\text { - ревматические заболевания (ревматизм, ревматоидный артрит, системная красная волчанка, васкулит, } \\
\text { склеродермия и др.) }\end{array}$ & Да & Нет \\
\hline
\end{tabular}

если да, то какие препараты принимаете по назначению врача

\section{- заболевания крови}

есть ли нарушение свертываемости крови

- заболевания нервной системы

были ли у Вас (Вашего ребенка) приступы эпилепсии?

если да, то что является провоцирующим фактором?

если да, то какие лекарственные препараты Вы (Ваш ребенок) принимаете

\section{- психические заболевания}

- остеопения/остеопороз

Были ли у Вас (Вашего ребенка) когда-нибудь переломы костей?

если да, то сколько и какие?

за последние 3 мес принимали ли Вы (Ваш ребенок) препараты для укрепления костей (Золендронат,

Клодронат и др)?

если да, то какие лекарственные препараты принимаете

Дата последнего измерения плотности кости (денситометрии)

-заболевания щитовидной железы

если да, то какой диагноз ставит эндокринолог (гипотиреоз, тиреотоксикоз)

какое лечение назначено эндокринологом

давность заболевания

как давно Вы делали анализы крови на содержание гормонов щитовидной железы?

-другие эндокринные заболевания

-онкологические заболевания

Есть ли у Вас (у Вашего ребенка) какие-то из перечисленных симптомов:

- сухость во рту;

- жажда;

-длительно не заживающие повреждения на коже или слизистой оболочке в полости рта;

Были ли у Вас (Вашего ребенка) аллергические реакции на лекарственные препараты?

\begin{tabular}{|l|l|}
\hline Да & Нет \\
\hline Да & Нет \\
\hline Да & Нет \\
\hline Да & Нет \\
\hline
\end{tabular}

если да, то на какие?

Были ли у Вас (Вашего ребенка) аллергические реакции на продукты питания, пыль, пыльцу растений,

шерсть животных, латекс, бижутерию, металл и др.?

\begin{tabular}{|l|l|}
\hline Да & Нет \\
\hline Да & Нет \\
\hline Да & Нет \\
\hline Да & Нет \\
\hline
\end{tabular}

\begin{tabular}{|l|l} 
Да & Нет \\
&
\end{tabular}


Таблица 1 (продолжение). Первичное анкетирование ортодонтического пациента. Рост/вес Возраст

\begin{tabular}{|c|c|c|}
\hline \multicolumn{3}{|l|}{ если да, то на что? } \\
\hline Страдаете ли Вы (Ваш ребенок) атопическим дерматитом? & Да & Нет \\
\hline \multicolumn{3}{|l|}{ если да, то что Вы (Ваш ребенок) применяет для лечения? } \\
\hline Есть ли непереносимость каких-либо пищевых продуктов? & Да & Нет \\
\hline \multicolumn{3}{|l|}{ если да, то каких? } \\
\hline \multicolumn{3}{|c|}{ Как Вы оцениваете уровень стресса, которому Вы (Ваш ребенок) подвергаетесь в повседневной жизни по шкале от 1 до $10 ?$} \\
\hline Страдаете ли Вы (Ваш ребенок) от депрессии? & Да & Нет \\
\hline Проводилась ли Вам (Вашему ребенку) когда-либо трансплантация органов? & Да & Нет \\
\hline Есть ли эндопротезы суставов? & Да & Нет \\
\hline Курите ли Вы (или Ваш ребенок)? & Да & Нет \\
\hline \multicolumn{3}{|l|}{ если да, то как давно и сколько сигарет в день? } \\
\hline \multicolumn{3}{|l|}{ Употребляете ли Вы (Ваш ребенок) кофе? (количество чашек и крепость в день) } \\
\hline Употребляете ли Вы (Ваш ребенок) алкоголь, наркотики? & Да & Нет \\
\hline \multicolumn{3}{|l|}{ Для женщин: } \\
\hline Наличие беременности & Да & Нет \\
\hline Кормление грудью & Да & Нет \\
\hline Применяете ли Вы противозачаточные препараты? & Да & Нет \\
\hline Менопауза & Да & Нет \\
\hline \multicolumn{3}{|l|}{ Если да, то в каком возрасте наступила менопауза } \\
\hline \multicolumn{3}{|c|}{ Перечислите все фармпрепараты, которые Вы (Ваш ребенок) регулярно принимает (название/дозировка) в виде: } \\
\hline - инъекций & Да & Нет \\
\hline - таблеток & Да & Нет \\
\hline - ингаляций & Да & Нет \\
\hline - спреев & Да & Нет \\
\hline Принимаете ли Вы (Ваш ребенок) регулярно БАДы, пищевые добавки, витамины, микроэлементы? & Да & Нет \\
\hline \multicolumn{3}{|l|}{ если да, то какие (указать название) } \\
\hline $\begin{array}{l}\text { Наблюдаются ли у Вас (Вашего ребенка) другие заболевания или медицинские проблемы, не пере } \\
\text { если да, то укажите какие }\end{array}$ & Іше & \\
\hline
\end{tabular}

Подпись пациента Дата

Заполнять анкету подлежит 1 раз в 6 мес

Повторный опрос Дата

Повторный опрос Дата

Повторный опрос Дата
Подпись

Подпись Подпись а так же возможность пациента самостоятельно заполнить анкету.

В последующем был проведен сравнительный анализ результатов опроса по двум анкетам.

\section{Результаты \\ исслеАОвания}

Для полноценного выявления общесоматических заболеваний, принимаемых лекарственных препаратов и других факторов, способных негативно отразиться на ортодонтическом лечении, в дополнении к разделам "Анамнез" и «Общий медицинский анамнез» медицинской истории болезни по форме № 043-1/y, нами было предложено предварительное анкетирова- ние пациентов, обратившихся на первичную консультацию к ортодонту.

Анкета включает в себя 68 вопросов, с помощью которых можно получить углубленную информацию о состоянии здоровья пациента. (Свидетельство о депонировании № 2051872). (Таб.1)

При сравнении данных анамнеза, полученных при заполнении медицинской карты формы № 043-1/y и разработанного нами опросника, были выявлены значительные отличия.

При самостоятельном заполнении анкеты информацию о приеме важных для ремоделирования костной ткани витаминных препаратов, таких как витамин 
D3, указали 65 пациентов (22,9\%), 48 человек -Омега-3 $(16,9 \%)$, препараты цинка указали в опроснике 5 человек $(1,8 \%)$. Тогда как при опросе, проводимым врачом на прием, прием витамина D3 указали лишь 20 человек (7\%), Омега-3-16 человек (5,6\%), о цинке не упомянул ни один пациент.

Среди всех опрошенных пациентов, 71 человек (25\%) рассказал о наличии изолированных или сочетании аллергий на лекарства, продукты питания, пыль, шерсть животных и поллинозы. При сравнении результатов опроса, полученных при личной беседе с врачом и при самостоятельном заполнении разработанного нами опросника, никаких отличий по количеству пациентов, сообщивших о наличии аллергий на медикаменты выявлено не было. (12 пациентов, 4,2\%). Среди препаратов, вызывающих аллергию, были названы антибиотики пенициллинового ряда, бисептол, вильпрафен, цефтриаксон, фолиевая кислота и др. Однако, при опросе врачом большинство пациентов не указали наличие немедикаментозных аллергических реакций (53 человека, 18,7\%). Кроме того, лишь в разработанном нами опроснике 7 пациентов сообщили о наличии атопического дерматита (2,5\%).

При заполнении врачом медицинской карты формы № 043-1/у ни один пациент не сообщил об остеопении/ остеопорозе, о наличии эндопротезов и о наличии менопаузы. Однако при анализе результатов заполнения опросника было выявлено 13 пациенток $(4,6 \%)$ в периоде менопаузы, 2 пациентки (0,7\%) с подтвержденным диагнозом остеопороза и 2 пациента $(0,7 \%)$ с эндопротезами коленного и тазобедренного суставов.

Прием лекарственных препаратов на постоянной основе отметили 64 пациента (22,5\%), как при опросе врача, так и при самостоятельном заполнении опросника. Однако, при сравнении двух вариантов сбора анамнеза было выявлено, что пациенты не одинаково отвечали на вопрос о приеме лекарств. Так, в разработанном нами опроснике 11 человек (3,9\%) указали прием стероидных противовоспалительных препаратов (Назанекс, Беродуал, Пульмикорт) в виде спреев или ингаляторно, не уведомив об этом врача-ортодонта при личной беседе, тогда как прием таких лекарственных средств способен влиять на метаболизм кости.

Разработанная анкета упрощает процесс сбора анамнеза, давая возможность самому пациенту заполнить её перед приемом у врача. Анкета будет акцентировать внимание врача на тех общих заболеваниях, которые способны влиять на процессы ремоделирования костной ткани самостоятельно или за счет лекарственных препаратов, применяемые для их лечения. Наличие вредных привычек, особенностей питания, прием пи- щевых добавок и уровень стресса в повседневной жизни так же отражены в анкете.

Формат анкеты содержит как уже заготовленные ответы, так и дает возможность пациенту самостоятельно указать дополнительные сведения.

Предварительное анкетирование позволяет пациенту не забыть сообщить врачу информацию, которая может оказаться очень важной для планирования дальнейшего ортодонтического лечения.

Таким образом, на момент первичной консультации ортодонт уже имеет представление о состоянии здоровья пациента и в личной беседе сможет задать лишь уточняющие вопросы, что поможет врачу существенно экономить рабочее время.

\section{Обсужление}

Влияние лекарственных препаратов и общесоматических заболеваний на процесс перемещения зубов известно давно и не подвергается сомнению. От умения врача правильно сформулировать вопросы для пациента будет зависеть получение максимально полной информации, что напрямую будет связано с успехом запланированного ортодонтического лечения.

Наше исследование показало, что многие пациенты, не понимая связи некоторых заболеваний, лекарственных препаратов и процесса ортодонтического лечения, не считают нужным информировать врача-ортодонта о таких диагнозах, как, например, остеопороз, менопауза, аллергические реакции, не связанные с приемом медикаментов и др.

Предложенная анкета содержит в себе вопросы по тем заболеваниям, которые, согласно литературным данным, способны непосредственно отразиться на физиологическом ремоделировании костной ткани. К таким заболеваниям можно отнести сахарный диабет. По статистическим данным, 3-4\% пациентов на рутинном ортодонтическом приеме имеют сахарный диабет [8]. Ортодонтическое лечение, проводимое у пациентов с декомпенсированным сахарным диабетом, может способствовать ускорению генерализованной деструкции тканей пародонтита [9]. Кроме того, уточняющие вопросы в анкете по основным симптомам и жалобам, характерным для диабета, позволят врачу, при необходимости, назначить пациенту дополнительные анализы для определения уровня глюкозы и гликированного гемоглобина, а так же направить на консультацию к эндокринологу.

Остеопороз - заболевание, характеризующееся системным и генерализованным снижением костной мас- 
сы, в том числе, и в области альвеолярных отростков. У пациентов с остеопорозом скорость ортодонтического перемещения зубов достоверно выше, по сравнению со здоровыми пациентами [10]. Однако и стабильность результата лечения скомпрометирована. Понимание особенностей течения подобного заболевания и мониторинг плотности костной ткани позволит врачу-ортодонту тщательно планировать ретенционный период [11].

Ряд хронических заболеваний влияют на костную ткань за счет нарушения метаболизма витамина D3, всасывания кальция и других необходимых нутриентов. Так, у пациентов с хроническими заболеваниями печени, почек, воспалительными заболеваниями кишечника, эндокринными нарушениями развивается вторичная остеопения/остеопороз, что необходимо принимать во внимание в процессе ортодонтического перемещения зубов $[12,13,14]$.

Вопрос о желудочно-кишечных заболеваниях (гастрит, язвенная болезнь) требуют уточнения о возможном присутствии симптома рефлюкса и приема антацидных препаратов (маалокс, альмагель, ренни и др.) или ингибиторов протонной помпы (омепрозол, пантопрозол и др.), которые при длительном применении способны вызывать повышенную резорбцию костей, что не может не сказаться на эффективности ортодонтического лечения [15]. Зачастую, пациенты не считают эти препараты лекарственными и не информируют врача об их применении.

Некоторые заболевания представляют опасность для пациента в процессе проведения стоматологических манипуляций. Врач-ортодонт должен быть информирован о возможных триггерах, провоцирующих приступы бронхиальной астмы или эпилепсии.

Кроме того, бронхиальная астма и другие аллергические заболевания различного генеза могут способствовать развитию патологической резорбции корней зубов в процессе ортодонтического лечения [16]. При беседе с врачом на вопрос о наличии аллергических реакций многие пациенты в настоящем исследовании отвечали отрицательно, однако при заполнении разработанного нами опросника выявлялся целый комплекс пищевых аллергий и/или поллинозы.

Известно, что ряд стоматологических манипуляций (снятие оттисков, пародонтологические операции, цементировка и снятие ортодонтических колец и др) способны вызвать транзиторную бактериемию и, в некоторых случаях, стать причиной возникновения инфекционного эндокардита [17]. Тщательный сбор анамнеза по кардиологическим заболеваниям позволит врачу ортодонту правильно оценить степень риска и по показаниям провести антибиотикопрофилактику [18].

Однако, не только сам патологический процесс, но и его лечение может отрицательно повлиять на процесс костного ремоделирования. В ходе устного опроса было выявлено ошибочное представление пациентов о том, что лекарственные препараты могут применяться только в виде инъекций или таблеток. В результате пациенты не упоминали о приеме лекарств в виде ингаляций, спреев и т.д. Разработанная нами анкета содержит уточняющие вопросы о способе приема препаратов, позволяющие пациенту предоставить врачу исчерпывающую информацию по лекарственному анамнезу.

Большое число заболеваний (аутоиммунные, воспалительные и др.) лечатся с помощью НПВС, кортикостероидных препаратов, цитостатиков, иммунодепрессантов. Данные препараты негативно влияют на костный метаболизм и способны отразиться на ходе ортодонтического лечения $[19,20]$. А прием таких препаратов, как бисфосфонаты, является противопоказанием к ортодонтическому перемещению зубов [10].

Ряд лекарственных препаратов, применяемых, например, при лечении эпилепсии и гипертонической болезни, способны вызвать гиперпластический гингивит, существенно затрудняющий гигиену, фиксацию съемных аппаратов и перемещение зубов в процессе ортодонтического лечения [21].

Различные пищевые добавки, которые, зачастую пациенты принимают самостоятельно, без назначения врача, так же могут влиять на процесс ремоделирования костной ткани, как ускоряя ее (витамин D3), так и, напротив, увеличивая минеральную плотность кости (цинк, витамин С, кальций и др.).

В нашем исследовании часто пациенты не упоминали регулярный прием пищевых добавок, считая эту информацию не существенной для врача-ортодонта. Разработанный нами опросник показал более высокий процент пациентов, длительное время применяющих различные добавки.

Современный ритм жизни накладывает отпечаток на психо-эмоциональное состояние пациентов. Субъективная оценка уровня стресса и состояния депрессии может быть важной для врача-ортодонта. Так, по мнению Mirzakouchaki B., [22], в условиях хронического стресса скорость ортодонтического лечения была достоверно ниже. Однако Gameiro G.H., [23] пришел к противоположному выводу. Правильный выбор ре- 
жима активации аппаратуры в каждом случае позволит избежать осложнений у данной категории пациентов.

Наличие вредных привычек, таких как курение или прием алкогольных напитков так же способны повлиять на ортодонтическое лечение. Хорошо известна прямая зависимость между курением и снижением минеральной плотности кости и воспалительными заболеваниями пародонта. Аналогичным побочным действием в отношении костной ткани обладает и этанол [24,25].

На сегодняшний день нет единого мнения о влиянии кофеина на костную ткань. Ряд авторов указывают на то, что чрезмерное употребление кофеина ассоциировано со снижением минеральной плотности кости и повышенным риском переломов [26], в то время как другие не обнаружили подобной взаимосвязи [27]. Несмотря на противоречивые данные, врачу-ортодонту следует принимать во внимание возможное влияние кофеина на процесс перемещения зубов и соответствующим образом корректировать биомеханику и режим активации.

Влияние эстрогена на метаболизм костной ткани хорошо изучено. Так, эстроген напрямую стимулирует синтез коллагена и образование костной ткани остеобластами, увеличение массы и плотности кости [28]. Гормональные препараты, содержащие эстроген и прогестерон, применяемые в целях контрацепции или для заместительной терапии в период менопаузы, способны снижать скорость ремоделирования костной ткани, и, в конечном итоге, замедлять перемещение зубов [29].
При применении стентов, эндопротезов, изготовленных из металла, содержащих в своем составе никель, возможно развитие сенсибилизации, что, в последствии, может привести к развитию аллергических осложнений при использовании ортодонтической аппаратуры с высокой концентрацией никеля [30].

\section{Выво $\triangle$}

Разработанный нами опросник показал повышенную эффективность при выявлении не медикаментозных аллергических реакций (на 18,7\%), менопаузы (4,6\%), остеопороза и наличия эндопротезов (на 0,7\%). С помощью предварительного анкетирования удалось выявить больше на 3,9\% пациентов, принимающих кортикостероиды в виде спреев или ингаляций, витамин $D_{3}$ (на 15,9\%), Омега 3 (на 11,3\%) и цинк (на 1,8\%).

Комплексный анализ данных анамнеза, полученные из опросника/анкеты, позволит врачу-ортодонту иметь более достоверные и полные сведения о состоянии здоровья пациента. Индивидуализированный план ортодонтического лечения, составленный с учетом общесоматического статуса и лекарственного анамнеза, позволит выбрать оптимальную биомеханику, своевременно выявить противопоказания, факторы риска и избежать осложнений.

Так как ортодонтическое лечение продолжительно и может занимать от 1,5 лет и более, важно периодически обновлять данные анамнеза.

\section{ЛИТЕРАТУРА}

1. Arqub S.A., Gandhi V., Iverson M.G., Ahmed M., Kuo C-L., et al. The effect of the local administration of biological substances on the rate of orthodontic tooth movement: a systematic review of human studies// Progress in Orthodontics. — 2021. — № 22.-P.5.

2. Bartzela TN, Maltha JC. Medication effects on the rate of orthodontic tooth movement. Biology of Orthodontic Tooth Movement// Springer.- 2016.-P.133-159.

3. Shroff B. Biology of orthodontic tooth movement: Current concepts and applications in orthodontic practice// Springer. - 2016.-P.13-44.

4. Jamali S. et al. Delay Factors Influenced of Orthodontic Treatment and its Consequences: A Meta-analysis and Systematic Review// Ann Med Health Sci Res. 2019.-Vol.9.-P.453-456.

5. Лапина, А.К. Оценка качества заполнения медицинской карты стоматологического больного на ортодонтическом приеме/А.К. Лапина// Стоматология.-2016 -№ 3.-С.85.

6. Лапина, А.К.Оценка качества заполнения медицинской документации в частных медицинских организациях/А.К. Лапина//Стоматология.-2017.-№ 3.-Т.96.-С.82.

7. Шерматова, Ю.В. Анкетирование пациентов как эффективный способ профилактики неотложных состояний в амбулаторной практике врача-стоматолога / Ю.В. Шерматова, В.В. Еричев, Т.В. Аксенова // «Медицинская наука и здравоохранение». Материалы XIV научно-практической конференции молодых ученых и студентов Юга России- Краснодар, 2016. - С. 119-121.

8. Watted N., Proff P., Peter B., Muhamad A-H. Influence of drugs on orthodontic tooth movement// Journal of Research in Medical and Dental Science. 2014. - Vol. 2(4). - P. 9-16.

9. Arita, K., Hotokezaka, H., Hashimoto, M., Nakano-Tajima, T., Kurohama, T., Kondo, T., Darendeliler, M.A. and Yoshida, N. Effects of diabetes on tooth movement and root resorption after orthodontic force application in rats// Orthodontics \& Craniofacial Research. — 2016.-Vol. 19. — P. 83-92.

10. Salazar M., Hernandes L., Ramos A.L., Salazar B.D.E.O., Micheletti K.R., Paranhos L.R., de Mendonça M.R. and Cuoghi 0.A. Effect of alendronate sodium on tooth movement in ovariectomized rats// Archives of Oral Biology.-2015. — Vol. 60.— P. 776-781. 
11. Seifi, M., Ezzati, B., Saedi, S. and Hedayati, M. The effect of ovariectomy and orchiectomy on orthodontic tooth movement and root resorption in wistar rats// Journal of dentistry (Shiraz, Iran). — 2-15. — № 16.—P. 302-309.

12. Nobile S., Richard G.J., Pappa H.M. Risk factors for low bone mineral density in pediatric inflammatory bowel disease: the positive role of physical activity// European Journal of Gastroenterology \& Hepatology. - 2018.-Vol.30(4).-P. 471-476.

13. Shirazi M, Khosrowshahi M, Dehpour AR. The effect of chronic renal insufficiency on orthodontic tooth movement in rats// Angle Orthod.- 2001.Vol.71(6). - P. 494-8.

14. Shirazi M, Ameri A, Shafaroodi H, Motahhary P, Saleh T, Ghasemi M, et al. Orthodontic tooth movement in cholestatic and cirrhotic rats// J 0rthod. — 2008. — Vol.35.-P. 119-125.

15. Andersen, B.N., Johansen, P.B. and Abrahamsen, B. Proton pump inhibitors and osteoporosis// Current Opinion in Rheumatology. — 2016.— Vol.28. P. $420-425$.

16. Sifakakis I., Eliades T. Adverse reactions to orthodontic materials// Australian Dental Journal. — 2017. — Vol. 62(1). — P. $20-28$.

17. Tekale P.D., Mhaske A.R., Acharya V.D., Patil H.A., Agarwal C.O., Aru B.M. Clinical management and guidelines of infective endocarditis in orthodontics// World J Dent. - 2015. - Vol. 6(4). - P. 226-228.

18. Vandersluis Y.R., Suri S. Infective endocarditis and orthodontic implications in children: A review of the literature// Am J Orthod and Dentofacial Orthop.2020. - Vol. 157(1). - P. 19-28.

19. Григорьева Н.В. Ятрогенный остеопороз. Часть I// Medicine of Ukraine. — 2018. — № 5-6 (221-222). — P. 30-37.

20. Григорьева Н.В. Ятрогенный остеопороз. Часть II// Medicine of Ukraine. — 2018. — № 8 (224). — P. 34-42.

21. Krishnan, V., Zahrowski, J.J. and Davidovitch, Z. The effect of drugs and diet on orthodontic tooth movement. In Krishnan, V., Davidovitch, Z. (eds.). Biological Mechanisms of Tooth Movement. Wiley-Blackwell, New Jersey, 2nd edn. 2015.—pp. 173-187.

22. Mirzakouchaki B, Firoozi F, Shahrbaf S. Effect of psychological stress on orthodontic tooth movement in rats// Med Oral Patol Oral Cir Bucal.- 2011.Vol.16.-e285-91.

23. Gameiro GH, Nouer DF, Pereira-Neto JS, Urtado MB, Novaes PD, de Castro M et al. The effects of systemic stress on orthodontic tooth movement// Aust Orthod J. - 2008. - Vol.24. - P. 121-8.

24. Kirschneck C, Maurer M, Wolf M, Reicheneder C, Proff P. Regular nicotine intake increased tooth movement velocity, osteoclastogenesis and orthodontically induced dental root resorptions in a rat model// Int J Oral Sci._ 2017. — Vol. 9(3).—P. 174-184.

25. Barcia J.M., Portoles S., Portoles L. Does Oxidative Stress Induced by Alcohol Consumption Affect Orthodontic Treatment Outcome?// Front Physiol. — 2017.— Vol. 8.-P. 22.

26. Tsuang YH, Sun JS, Chen LT, Sun SC, Chen SC. Direct effects of caffeine on osteoblastic cells metabolism: the possible causal effect of caffeine on the formation of osteoporosis// J Orthop Surg Res. - 2006. - Vol. 1.—P. 7.

27. Duarte PM, Marques MR, Bezerra JP, Bastos MF. The effects of caffeine administration on the early stage of bone healing and bone density A histometric study in rats// Arch Oral Biol._ 2009. - Vol. 54. - P. 717-722.

28. Susilo SG, Amtha R, Roeslan B0, Kusnoto J. The differences of orthodontic tooth movement on menstrual and ovulation cycle// Dent. J.- 2014. - Vol. 47(4). - P. 177-80.

29. Olyaee P, Mirzakouchaki B, Ghajar K, et al. The effect of oral contraceptives on orthodontic tooth movement in rat// Med Oral Patol Oral Cir Bucal. - 2013. Vol. 18. - P. e146-50.

30. Zigante M., Mlinaric M.R., Kastelan M., Perkovic V., Zrinski M.T., Spalj S. Symptoms of titanium and nickel allergic sensitization in orthodontic treatment// Progress in Orthodontics.-2020. - Vol. 21. - P. 17 